\title{
Relationship between myocardial scar and hypertrophy by LGE CMR in hypertrophic cardiomyopathy patients with and without clinical events
}

\author{
Aya Kino ${ }^{1 *}$, Lubna Choudhury², James Carr ${ }^{1}$ \\ From 15th Annual SCMR Scientific Sessions \\ Orlando, FL, USA. 2-5 February 2012
}

\section{Summary}

The purpose of this study was to investigate the relationship between the extent of hyperenhancement and left ventricle maximal wall thickness (mWT) detected by LGE CMR and clinical events of nonsustained ventricular tachycardia (NSVT), implantation of cardioverter defibrillator (ICD) or diastolic heart failure in HCM patients that underwent LGE CMR.

\section{Background}

Late gadolinium enhancement cardiac magnetic resonance (LGE CMR) imaging has been used to detect myocardial hypertrophy and scar/fibrosis in Hypertrophic cardiomyopathy (HCM) patients. The presence of hyperenhancement has been associated with progressive ventricular dilation, ventricular arrhythmias and clinical risk factors for sudden cardiac death.

\section{Methods}

Under IRB approved protocol a total of $82 \mathrm{HCM}$ patients underwent LGE CMR images using a 2D PSIR TurboFLASH protocol after administration of $0.2 \mathrm{mmol}$ of gadopentetate dimeglumine per kilogram of body weight. The presence of LGE was assessed using automated software: percentage of scar and maximal wall thickness were calculated. Percentage of scar was compared between patients with $\mathrm{mWT}<2.5 \mathrm{~cm}$ and $\geq 2.5 \mathrm{~cm}$ The mean values of percentage scar and mean maximal wall thickness between patients with/ without clinical

${ }^{1}$ Radiology, Northwestern University, Chicago, IL, USA

Full list of author information is available at the end of the article events (presence of NSVT, placement of ICD or development of diastolic heart failure) were compared.

\section{Results}

Scar was detected in $74.5 \%$ patients and clinical events were present in 54 (\%) patients. Only one patient without scar had NSVT and had ICD implanted. There was a significant difference between $\mathrm{mWT}$ in patients with scar $(2.0 \mathrm{~cm})$ and no scar $(1.5 \mathrm{~cm}) \mathrm{p}=0.002$. Scar \% and mean $\mathrm{mWT}$ were significant higher in patients with positive clinical events(Table 1.There was no significant difference between $\%$ of scar in patients with risk factors when compared the mWT $\geq 2.5 \mathrm{~cm}$ and $<2.5 \mathrm{~cm}$. However patients with positive clinical events with $\mathrm{mWT} \geq 2.0 \mathrm{~cm}$ presented higher scar \% compared to patients with positive clinical events with $\mathrm{mWT}<2.0 \mathrm{~cm}$ (Table2).

\section{Conclusions}

In conclusion, $\mathrm{HCM}$ patients with a mWT above $2.5 \mathrm{~cm}$ maybe at increased risk of events regardless of the amount of myocardial scar.

\section{Funding}

None.

\section{Author details}

${ }^{1}$ Radiology, Northwestern University, Chicago, IL, USA. ${ }^{2}$ Department of Medicine, Cardiology Division, Northwestern University/Feinberg School of Medicine, Chicago, IL, USA.

Published: 1 February 2012 
Table 1 Relationship between \% SCAR/ mean wall thickness in HCM and clinical events

\begin{tabular}{cccc}
\hline & $\begin{array}{c}\text { Clinical events } \\
+\end{array}$ & $\begin{array}{c}\text { Clinical events } \\
-\end{array}$ & $\begin{array}{c}\mathrm{p} \\
\text { value }\end{array}$ \\
\hline \%SCAR & 30.49 & 17.26 & 0.001 \\
$\begin{array}{c}\text { Mean Maximal wall thickness } \\
(\mathrm{cm})\end{array}$ & 2.087 & 1.723 & 0.006 \\
\hline
\end{tabular}

Table 2 Comparison between Scar \% and clinical events with $\mathrm{mWT}$ of 2.0 or $2.5 \mathrm{~cm}$

\begin{tabular}{cccc}
\hline \multicolumn{4}{c}{ Clinical events +} \\
\hline mWT $<2.0 \mathrm{~cm}$ & $\mathrm{mWT} \geq 2.0 \mathrm{~cm}$ \\
\hline SCAR & 25.21 & 36.16 & 0.006 \\
\hline \% SCAR & $\mathrm{mWT}<2.5 \mathrm{~cm}$ & $\mathrm{mWT} \geq 2.5 \mathrm{~cm}$ \\
\hline
\end{tabular}

doi:10.1186/1532-429X-14-S1-P165

Cite this article as: Kino et al:: Relationship between myocardial scar and hypertrophy by LGE CMR in hypertrophic cardiomyopathy patients with and without clinical events. Journal of Cardiovascular Magnetic Resonance 2012 14(Suppl 1):P165.

Submit your next manuscript to BioMed Central and take full advantage of:

- Convenient online submission

- Thorough peer review

- No space constraints or color figure charges

- Immediate publication on acceptance

- Inclusion in PubMed, CAS, Scopus and Google Scholar

- Research which is freely available for redistribution

Submit your manuscript at www.biomedcentral.com/submit
C Biomed Central 